\section{RECEIVEO}

LAWRENCE

RADIATION LABORATORY

\section{DES 1972}

LIBRARY ANO

DOCUMENTS SECTION
LBL-1321

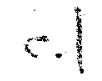

\title{
LIQUID-XENON-FILLED WIRE CHAMBERS
}

S.E. Derenzo, R. Flagg, S.G. Louie, F.G. Mariam, T.S. Mast

A.J. Schwemin, R.G. Smits, H. Zaklad, L.W. Alvarez, and R. A. Muller

September 1972

\section{For Reference}

Not to be taken from this room

Prepared for the U.S. Atomic Energy

Commission under Contract W-7405-ENG-48 
IIQUID -XENON-FILLED WIRE CHAMBERS*

S. E. Derenzo, R. Flagg, S. G. Louie, F. G Mariam, ${ }^{\dagger}$ T. S. Mast, A. J. Schwemin, R. G. Smits, H. Zaklad, and L. W. Alvarez

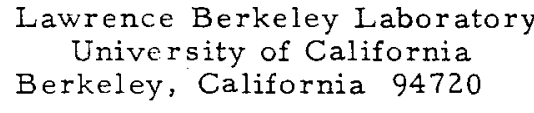

\section{R. A. Muller}

Space Sciences Laboratory

University of California

Berkeley, California 94720

\section{September 1972}

\section{ABSTRACT}

We describe several types of small liquid xenon-filled chambers, each optimized for a particular property such as a real-time spatial resolution of $\pm 15 \mu$, a time resolution of $\pm 10^{-7} \mathrm{sec}$, or a pulse height of $10^{-12}$ coulomb. Larger chambers combining all these properties will be of great value at NAL energies, and we describe some of the techniques necessary for their construction.

\section{Introduction}

In 1968, Luis Alvarez suggested that a filmless particle detector with $\pm 10 \mu$ space resolution could be developed by using a liquified noble gas as the detection medium. (1) He reasoned that a thousandfold increase in density (when compared with gas-filled wire chambers) would simultaneously permit a decrease in detector thickness and an increase in ion statistics. Other resolution-limiting factors such as electron diffusion and $\delta$-rays would also be significantly reduced. Operation at one atmosphere pressure would allow the technique to be used over large areas and readout would be simplified if the initial ionization could be amplified in the liquid.

\section{Single-Wire Chambers}

We have been operating liquid xenon-filled single-wire proportional chambers for two years. ${ }^{(2,3)}$ Figure 1 shows our single-wire chamber design, and Fig. 2 shows the pulse height of the $279-\mathrm{keV}$ photopeak as a function of operating voltage for $2.9-, 3.5-$, and $5.0-\mu$ anode wires. The chamber counts well and the pulse-height curves are reproducible to $\pm 10 \%$ every time the chamber is filled.

As mentioned in Ref. 2, the single-wire chamber produces two classes of avalanche pulses. The first type is proportional in size to the initial ionization and rises in $\sim 2 \times 10^{-7} \sec$ (see Fig. 3A). The second "Geiger" type is larger $\left(\sim 2 \times 10^{-12} \mathrm{C}\right)$, uniform in size, and rises more rapidly (see Fig. 3B). The rise time shown in Fig. 3B is limited by the rise time of our charge amplifier. When the "Geiger" pulses are observed directly on an oscilloscope, the true rise time of $\sim 10^{-8}$ sec may be seen (see Fig. 4 ).

Using the two collinear gamma rays from a ${ }^{22} \mathrm{Na}$ source, we measured the time resolution of a single-wire liquid xenon chamber to be $\pm 10^{-7}$ sec. During this test electronegative impurities restricted the effective diameter of the chamber to approximately $1 \mathrm{~mm}$. For details see Ref. 5 .

For decades the gas filling in wire chambers has included quenching agents to suppress sparking and to increase the size of the pulses. We have found that $\sim 2000$ ppm ethylene $\left(\mathrm{C}_{2} \mathrm{H}_{4}\right)$ in liquid xenon also permits higher operating voltage and larger pulses. This comparison is shown in Fig. 5.

\section{Multi - Wire Proportional Chambers}

We have designed and built a liquid xenon multi-wire proportional chamber specifically for detecting gamma rays in nuclear medicine. 
(For gamma rays in the $0.15-$ to $10-\mathrm{MeV}$ range this approach provides an unprecedented combination of detection efficiency, spatial resolution, and potential for up-scaling. $)^{(4)}$ This chamber is shown in Fig. 6 and consists of $243.5-\mu$ wires spot-welded to kovar pins sealed with glass to holes in the ceramic base. (4a) The wires are spaced $2.8 \mathrm{~mm}$ apart, and the wire plane is centered between two cathode planes spaced $15 \mathrm{~mm}$ apart. The gross detection efficiency for $280-\mathrm{keV}$ gamma rays is $65 \%$. At an operating potential of $-4500 \mathrm{~V}$ the liquid gain is 10 , and under these conditions the spatial resolution was measured to be $3 \mathrm{~mm}$ FWHM, demonstrating that the wires amplify independently without the addition of a quenching agent.

For the development of a chamber possessing high spatial resolution for charged particles, however, it is very important to demonstrate amplification by arrays of much more closely spaced wires. To this end we ran three arrays of five wires $3.5 \mu$ in diameter with spacings of 150,300 , and $1000 \mu$ between opposing cathodes spaced 5 mm apart in a small test chamber. With a $1000-\mu$ spacing, gain sets in at $3800 \mathrm{~V}$, reaching 10 at $5000 \mathrm{~V}$. A further increase in voltage at the $1000-\mu$ spacing and observation of gain at the $150-$ and $300-\mu$ spacings was prevented by the occurrence of sparks between the flat cathode and the wires of the anode. Very recently we have learned that these sparks are initiated by field emission from the cathode. We will continue studies with closely spaced anodes (50 to $300 \mu$ apart) using specially polished cathodes and the addition of ethylene to suppress sparking and provide larger gain.

In previous papers we have reported on schemes for producing closely spaced narrow conducting strips on an insulating substrate. Heidenhain Corporation can produce sub-micron chrome lines on glas or Mylar. (6) In addition, we have made Noryl ${ }^{(7)}$ pressings with sharp ridges $50 \mu$ apart and then vacuum deposited metal at a grazing angle to produce conductive strips several $\mu$ wide at the top of the ridges (see Fig. 7).

Recently we have devised a method of attaching fine wire to a substrate in such a way that $98 \%$ of the wire does not touch the substrate. A Noryl pressing is made, producing sharp ridges $100 \mu$ wide, $100 \mu \mathrm{high}$, and $1 \mathrm{~mm}$ apart. Then $5-\mu$ wire is wound around the ridges at right angles. The assembly is placed in a magnetic field while a current is passed through the wire. This serves to heat the wire and press it into the edge of the ridge. The result is shown in Fig. 8. Multi-Wire Ionization Chambers

Electron avalanche in the liquid is essential in reducing the complexity and cost of the readout. It is quite possible, however, using present technology, to build a liquid-xenon multi-wire ionization chamber having no liquid gain with a space resolution of $\pm 10 \mu$ and a time resolution of $\pm 20 \mathrm{nsec}$. Unfortunately the readout requires that a lownoise charge-sensitive amplifier be attached to each wire, increasing the cost by approximately $\$ 20$ per wire, and severely limiting its applications in physics experiments. Figure 9 shows the excellent spatial resolution that we have measured for the ionization mode. $(2,8)$

\section{Gamma-Ray Detection}

The density and atomic number of liquid xenon make it attractive for the absorption and detection of gamma-rays. In order to study the energy resolution obtainable, we built an ionization chamber with a Frisch grid. The chamber and experimental setup are shown in Fig. 10. The best resolution for $279-\mathrm{keV}$ gamma-rays obtained thus far is $10.5 \%$ FWHM (shown in Fig. 11), comparable to NaI(T1). The amount 
of liquid xenon required for the absorption of a multi-GeV electromagnetic shower is quite expensive $(\$ 3 / c c)$, but there is hope for the

future. For every megawatt-year generated by nuclear power reactors, 57 grams of Xe are produced. The only important contamination is $10.76-\mathrm{yr}^{85} \mathrm{Kr}$, which can be reduced to levels of $10 \mathrm{pCi}$ per STP liter Xe by distillation followed by a series of dilutions (with atmospheric Kr) and redistillations. C. A. Rohrmann (9) estimates that by 1980 the annual recovery of xenon will exceed 10 tons per year at a cost of $25 \not$ per liquid cc.

\section{Summary}

We have developed several versions of liquid-xenon-filled chambers, each optimized for a particular property such as unexcelled realtime spatiall resolution $( \pm 15 \mu)$, good energy resolution ( $\pm 5 \%$ for 279 $\mathrm{keV}$ gamma-rays), good pulse height $\left(10^{-12}\right.$ coulomb for minimum ionizing particles passing through $0.7 \mathrm{~mm}$ liquid $\mathrm{Xe}$ ), or good time resolution ( $\pm 10^{-7}$ sec for a $1-\mathrm{mm}$-thick chamber). We are working on the technology to allow us to combine several such properties in chambers covering useful areas.

\section{Acknowledgments}

We are indebted to Joe Savignano, Tony Vuletich, and Buck Buckingham for essential contributions to all phases of this work. This work was supported in part by the U. S. Atomic Energy Commission and in part by NASA.

Appendix

\section{Selected Properties of Liquid Xenon}

Boiling point

Freczing point

Density

STP gas/boiling-liquid volume ratio

$\mathrm{e}^{-}$drift velocity ${ }^{(10)}$

Ion pairs per $100 \mu$

Energy loss per $100 \mu$

Radiation length

Collision length

Present cost $-108.10^{\circ} \mathrm{C}$ (1 atm)

$-111.8^{\circ} \mathrm{C}(1 \mathrm{~atm})$

$$
3.057 \mathrm{~g} / \mathrm{Cc}
$$

518.9 (1 atm)

$\left\{\begin{array}{l}1 \times 10^{5} \mathrm{~cm} / \mathrm{sec} \text { at } 60 \mathrm{~V} / \mathrm{cm} \\ 2 \times 10^{5} \mathrm{~cm} / \mathrm{sec} \text { at } 500 \mathrm{~V} / \mathrm{cm} \\ 3 \times 10^{5} \mathrm{~cm} / \mathrm{sec} \text { from }\end{array}\right.$ 3 to $60 \mathrm{kV} / \mathrm{cm}$

2000 (minimum ionization)

$43 \mathrm{keV}$ (minimum ionization)

$25 \mathrm{~mm}$

$450 \mathrm{~mm}$

$\$ 3 / \mathrm{cc}$ 


\section{Footnotes and References}

*Work done under the auspices of the U. S. Atomic Energy Commission.

${ }^{\dagger}$ Participation made possible through a scholarship of the AfricanAmerican Institute.

1. L. W. Alvarez, Lawrence Radiation Laboratory, Group A

Physics Note No. 672, 1968 (unpublished).

2. R. A. Muller, S. E. Derenzo, G. Smadja, D. B. Smith, R. G. Smits, H. Zaklad, and L. W. Alvarez, Phys. Rev. Letters 27, 532 (1971).

3. Recently workers at Dubna have reported some excellent new results using a single-wire proportional chamber filled with high-pressure gases and solidified noble gases: A. F. Pisarev, V. F. Pisarev, and G. S. Revenko, Dubna Reports JINR - P13 - 6450 and JINR - P13 6449 (1972).

4. H. Zaklad, S. E. Derenzo, R. A. Muller, G. Smadja, R. G. Smits, and L. W. Alvarez, Trans. IEEE NS-19, 206 (1972).

4a. The 3.5- $\mu$ wires were spot-welded with a Model MCW-550 welding power supply and a Model VTA-90 welding head, both manufactured by Hughes Aircraft Company, Oceanside, California.

5. S. E. Derenzo, D. B. Smith, R. G. Smits, H. Zaklad, L. W. Alvarez, and R. A. Muller, Lawrence Radiation Laboratory Report UCRL-20118, which is the same as NAL Summer Study Report SS-181 (1970).

6. Heidenhain Corporation, 8225 Traunreut, W. Germany.

7. Noryl is a class of the rmoplastic resins manufactured by General Electric, Noryl Avenue, Selkirk, New York 12158.

8. The collimated alpha source used in Ref. 2 is described in I.awrence Radiation Laboratory Report UCRL-20857 (1971).
9. C. A. Rohrmann, Isotopes and Radiation Technology 8 , No. 3 , 253 (1971).

10. L. Miller, S. Howe, and W. Spear, Phys. Rev. 166, 871 (1968). 


\section{Figure Captions}

Fig. 1. Liquid-xenon single-wire proportional chamber.

Fig. 2. Pulse height vs voltage in liquid-xenon single-wire proportional chamber with 8 -mm-diam cathode and $2.9-, 3.5-$, and $5.0-\mu$-diam anodes. Signal is $279-\mathrm{keV}$ photopeak from ${ }^{203} \mathrm{Hg}$ source.

Fig. 3. Pulses from chamber of Fig. 1 seen on a charge amplifier with a gain of $0.4 \mathrm{~V} / \mathrm{pC}$.
A: proportional pulse,
B: "Geiger" pulse.

Fig. 4. "Geiger" -type pulses from chamber of Fig. 1 seen directly on an oscillos cope.
A: 1 -megohm load,
B: 125 -ohm load.

Fig. 5. Pulse height vs voltage in single-wire chamber for $5-\mu$ anode in pure liquid xenon and in liquid xenon containing $\sim 2000 \mathrm{ppm}$ $\mathrm{C}_{2} \mathrm{H}_{4}$.

Fig. 6. Gamma-ray chamber $15 \mathrm{~mm}$ thick, containing 243.5 - $\mu$-diam wires and 24 cathode strips.

A: shows ceramic chamber wall and support for anode wires and cathode strips,

B: shows as sembled chamber.

Fig. 7. Array of conducting strips produced by vacuum-depositing metal at a grazing angle onto a series of Noryl ridges $40 \mu$ wide and $100 \mu$ apart.

Fig. 8. Array of $5-\mu$ wires bonded to Noryl ridges $1 \mathrm{~mm}$ apart. Cur rent is passed through the wire in a magnetic field to heat the wire and press it into the ridges.

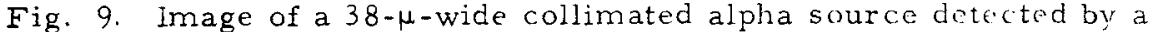
$0.7-\mathrm{mm}$-thick liquid-xenon ionization chamber. (See Refs. 2 and 6 for details.

Fig. 10. Liquid-xenon ionization chamber with Frisch grid and collimated gamma source.

Fig. 11. Pulse-height spectrum for $279-\mathrm{keV}$ gamma rays seen in setup of Fig. 10. FWHM is $10.5 \%$, comparable to NaI(T1). 


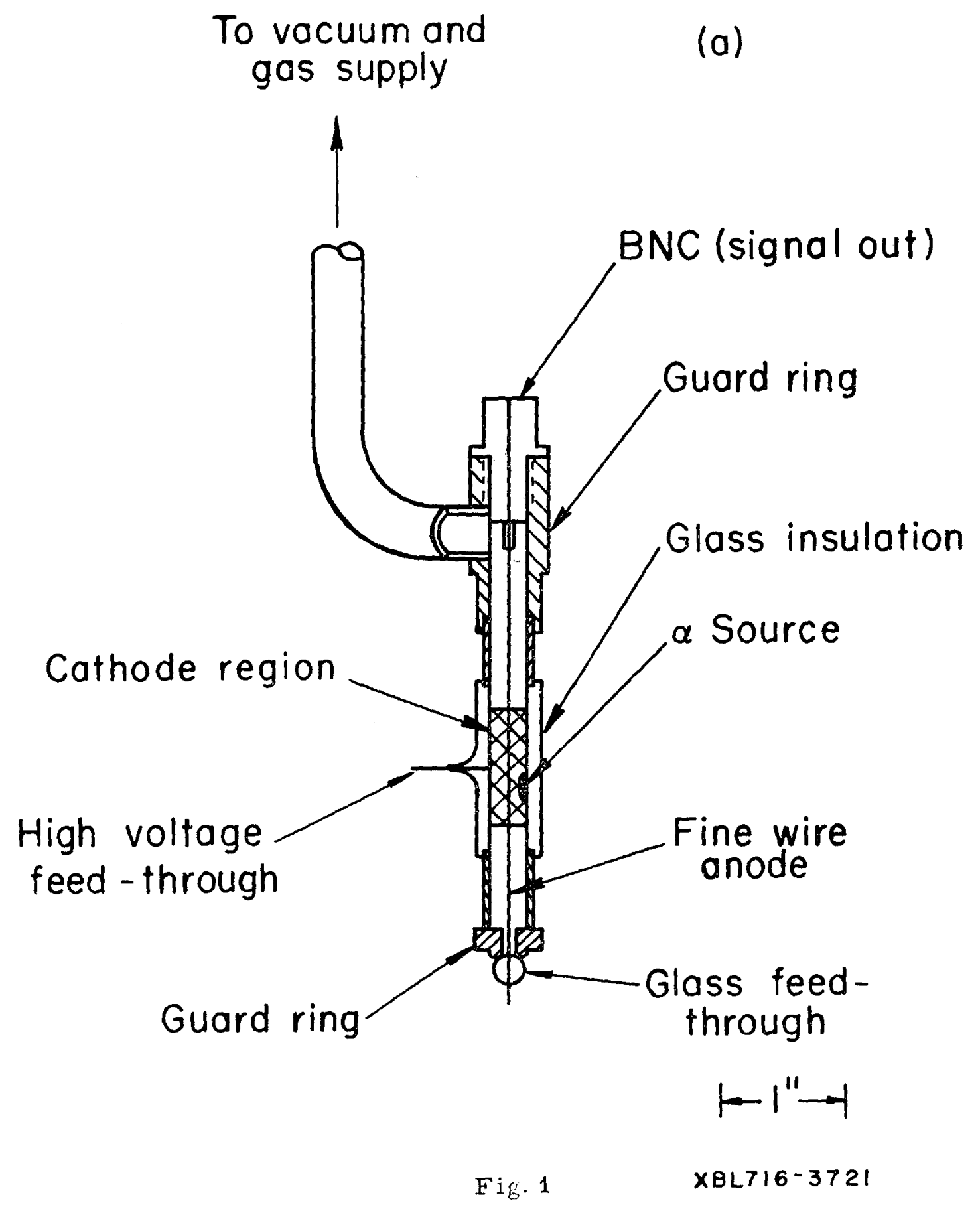




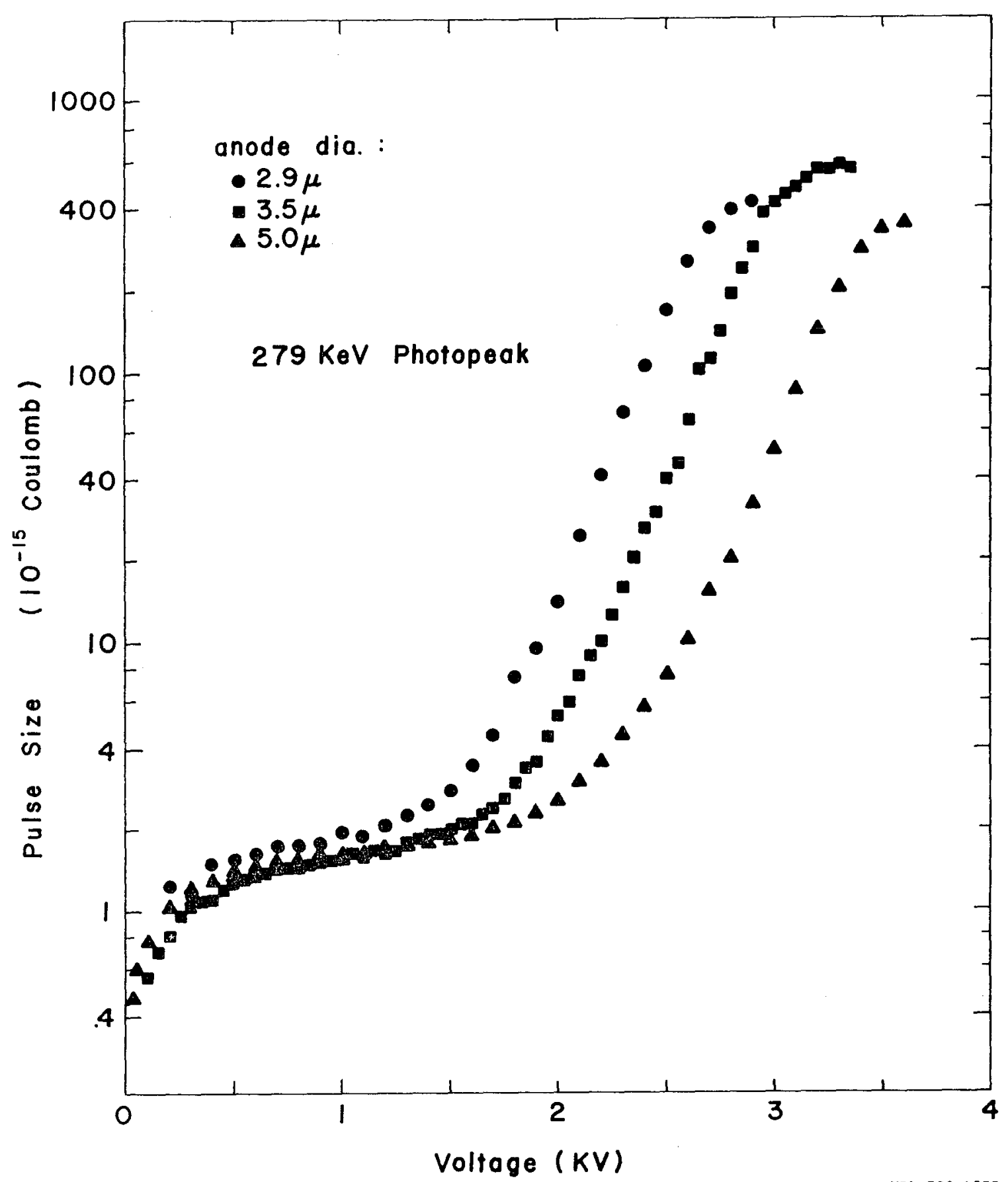

Fig. 2 

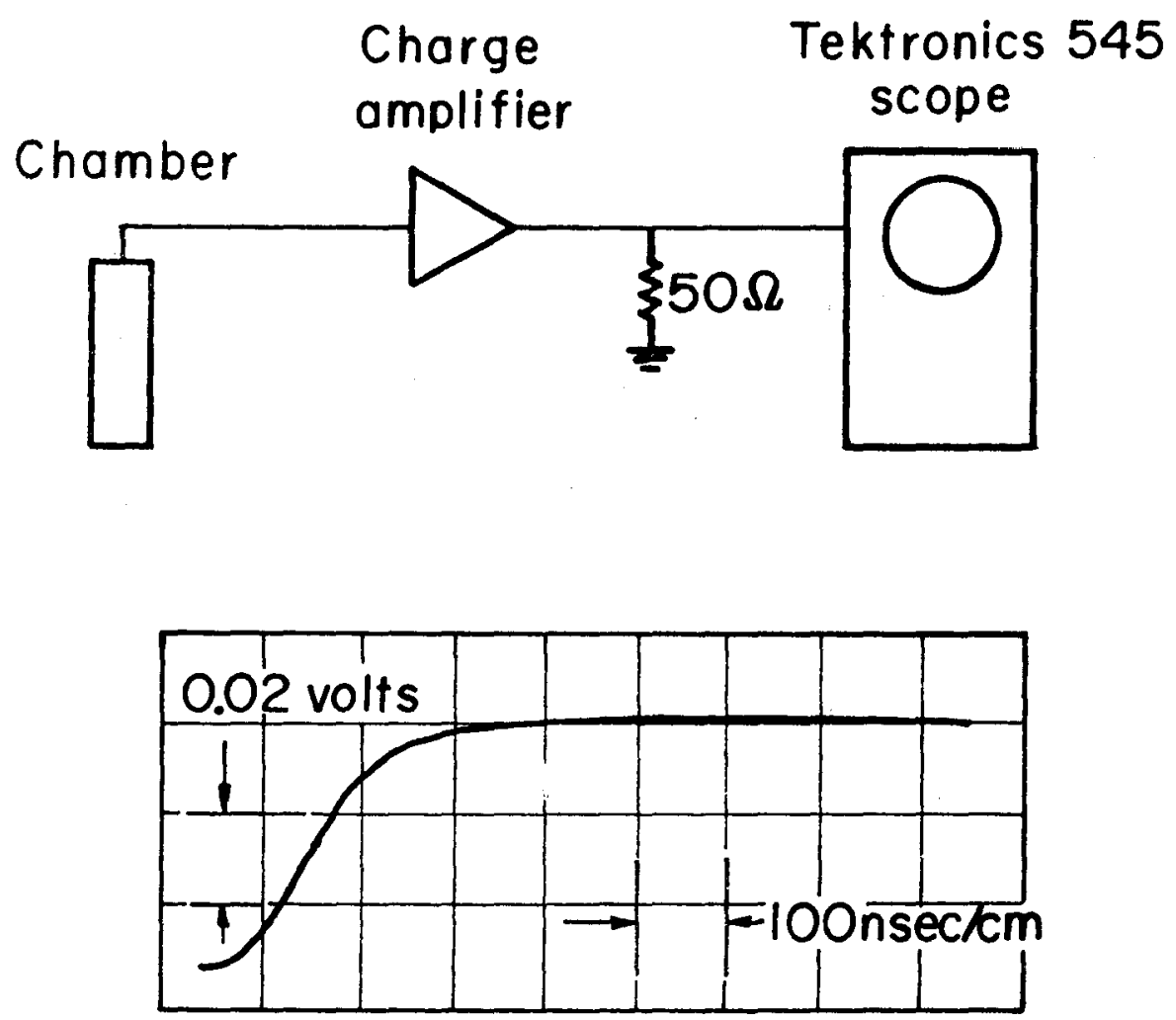

A

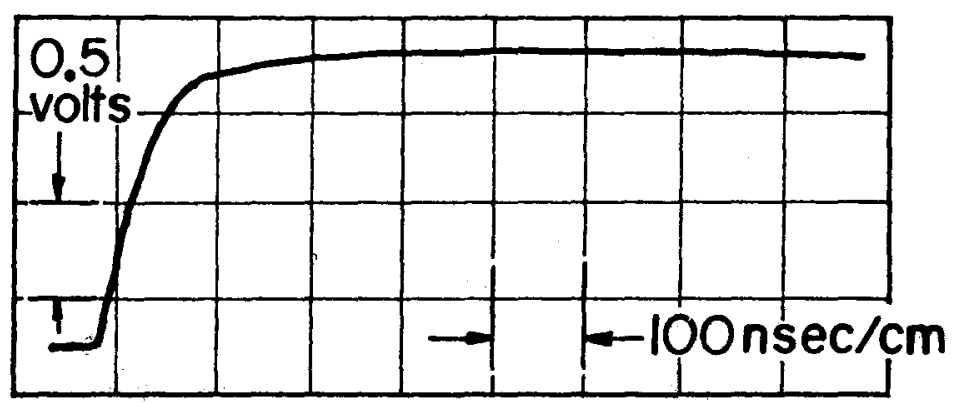

B

Fig. 3

XBL719-4266 
Tecktronics 545 scope

Chamber
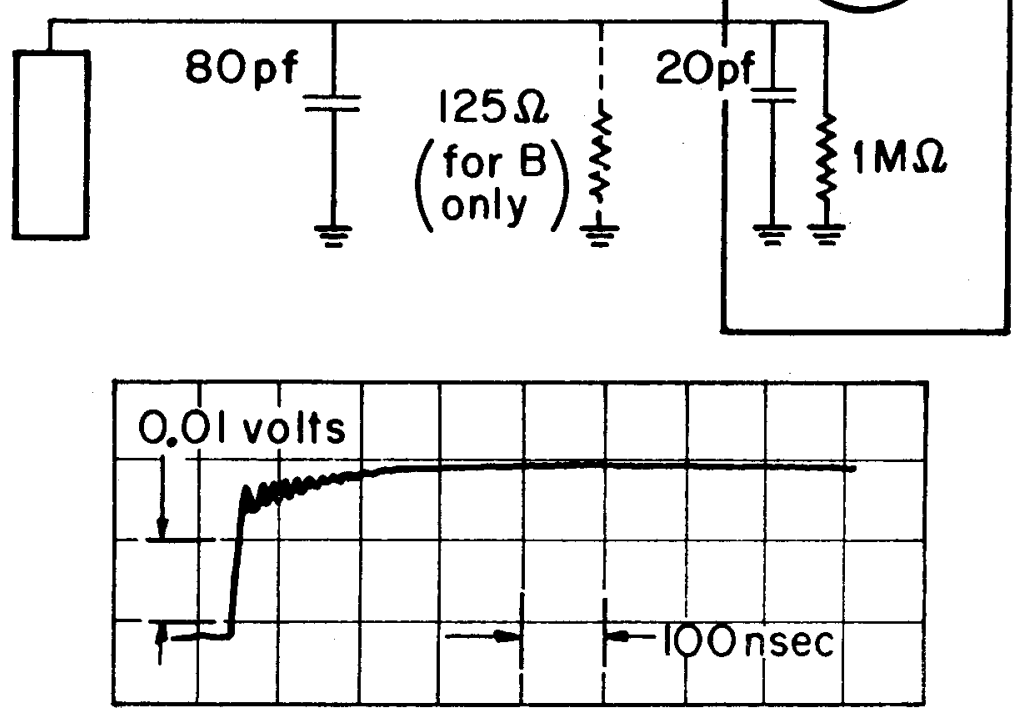

A

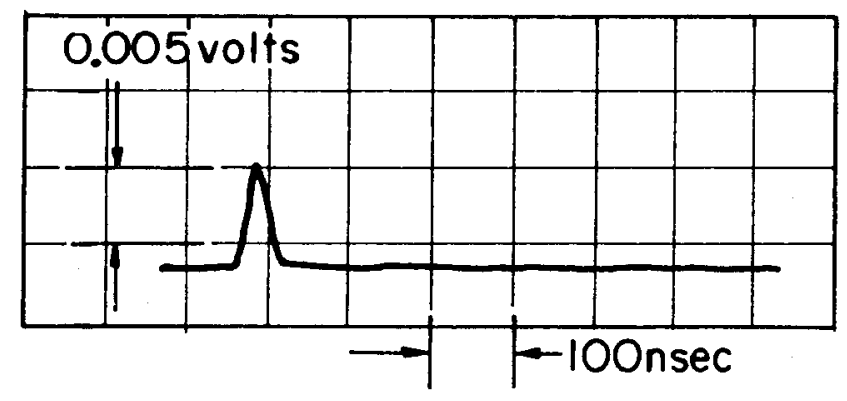

B

Fig. $4 \quad X B L 719-4265$ 


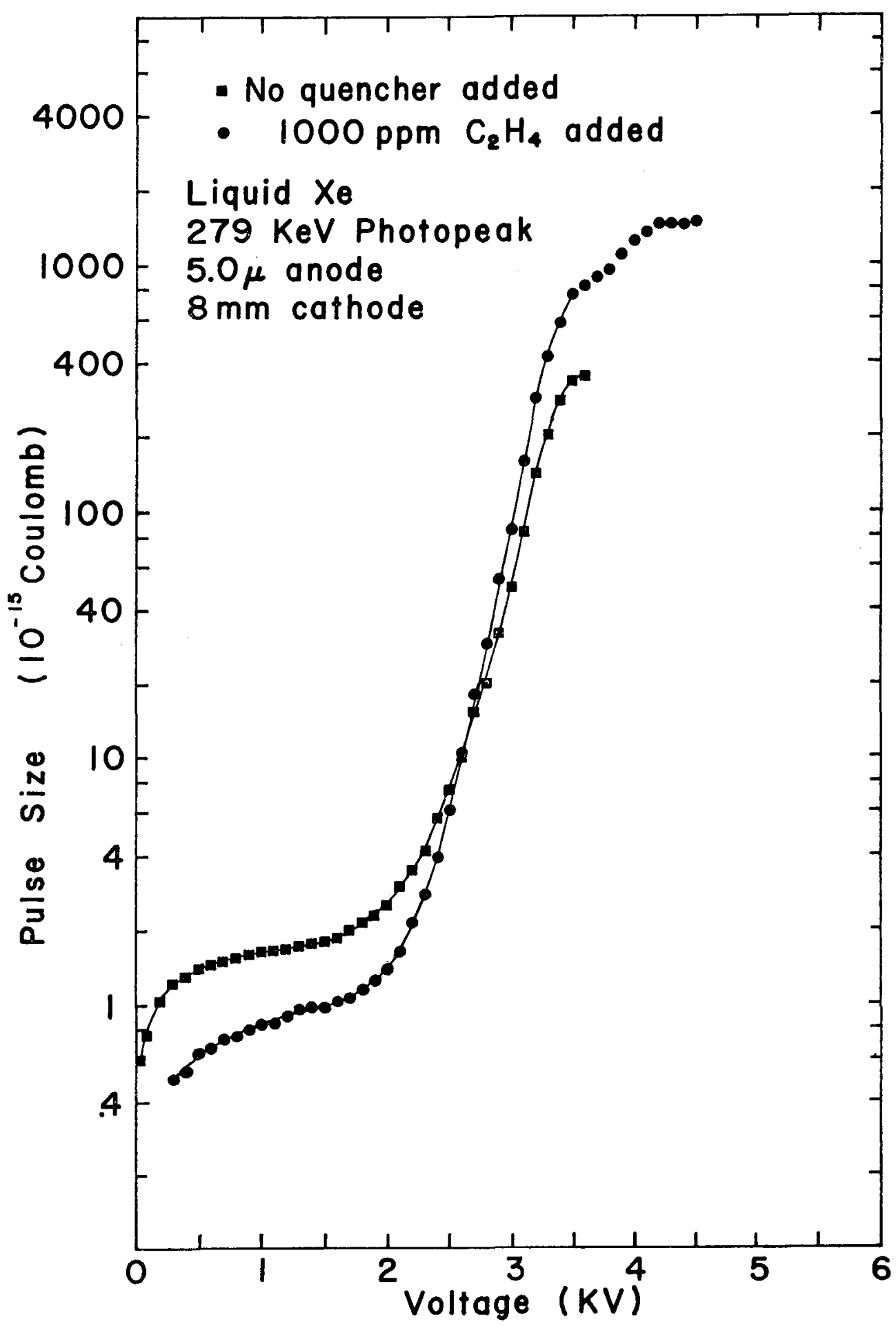

Fig. 5 


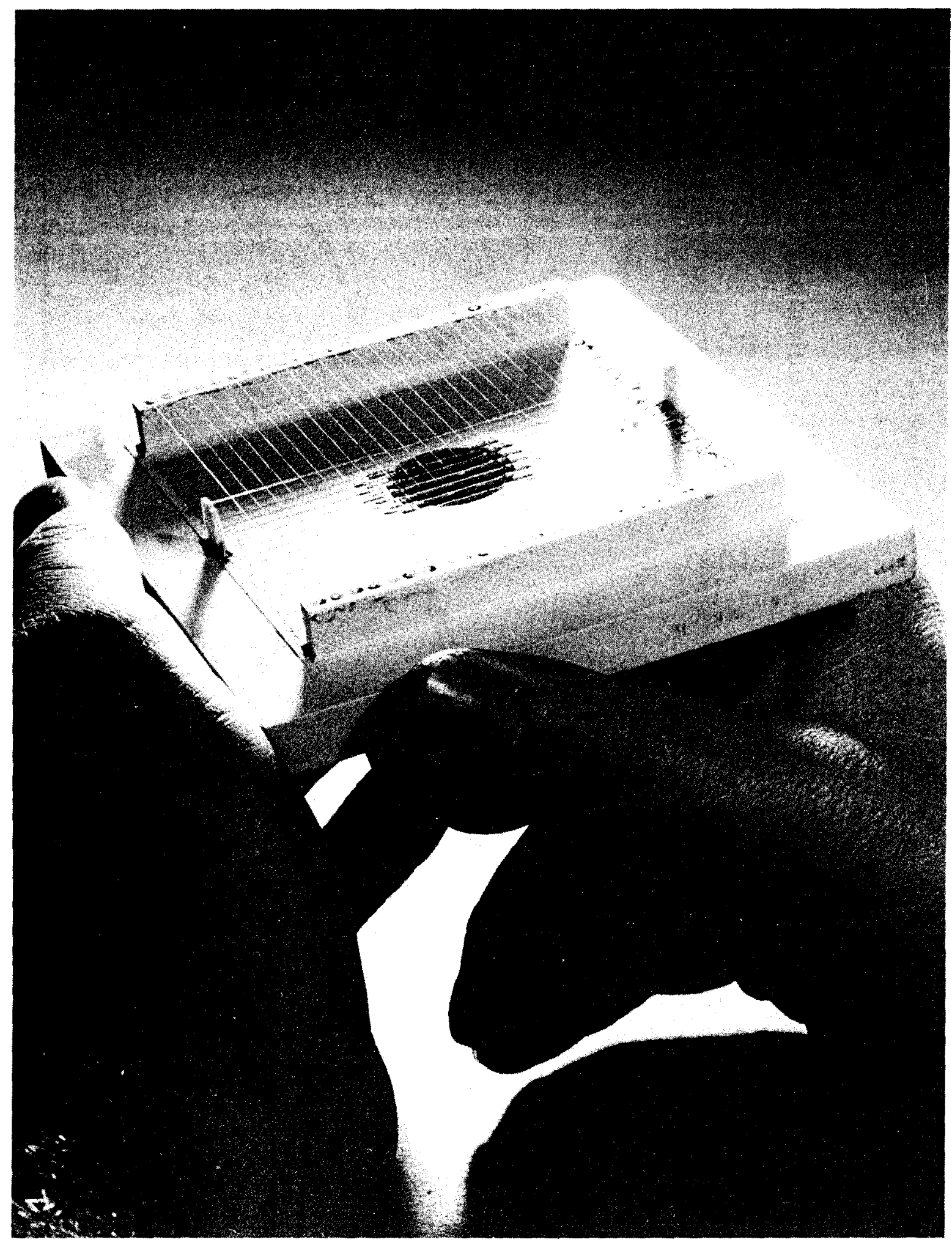

Fig. 6a

CBB 729-4305 


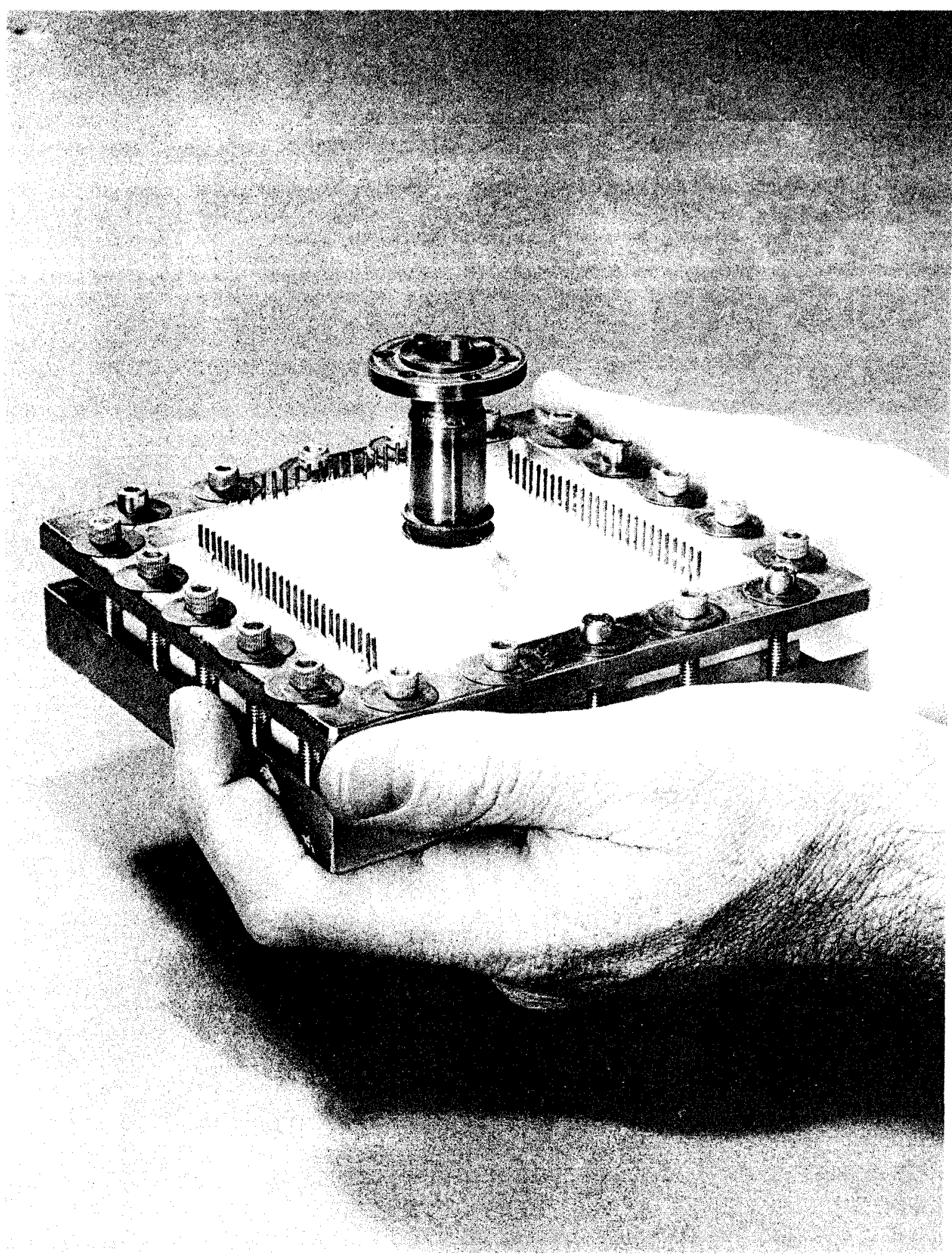

Fig. 6b

XBB 729-4307 


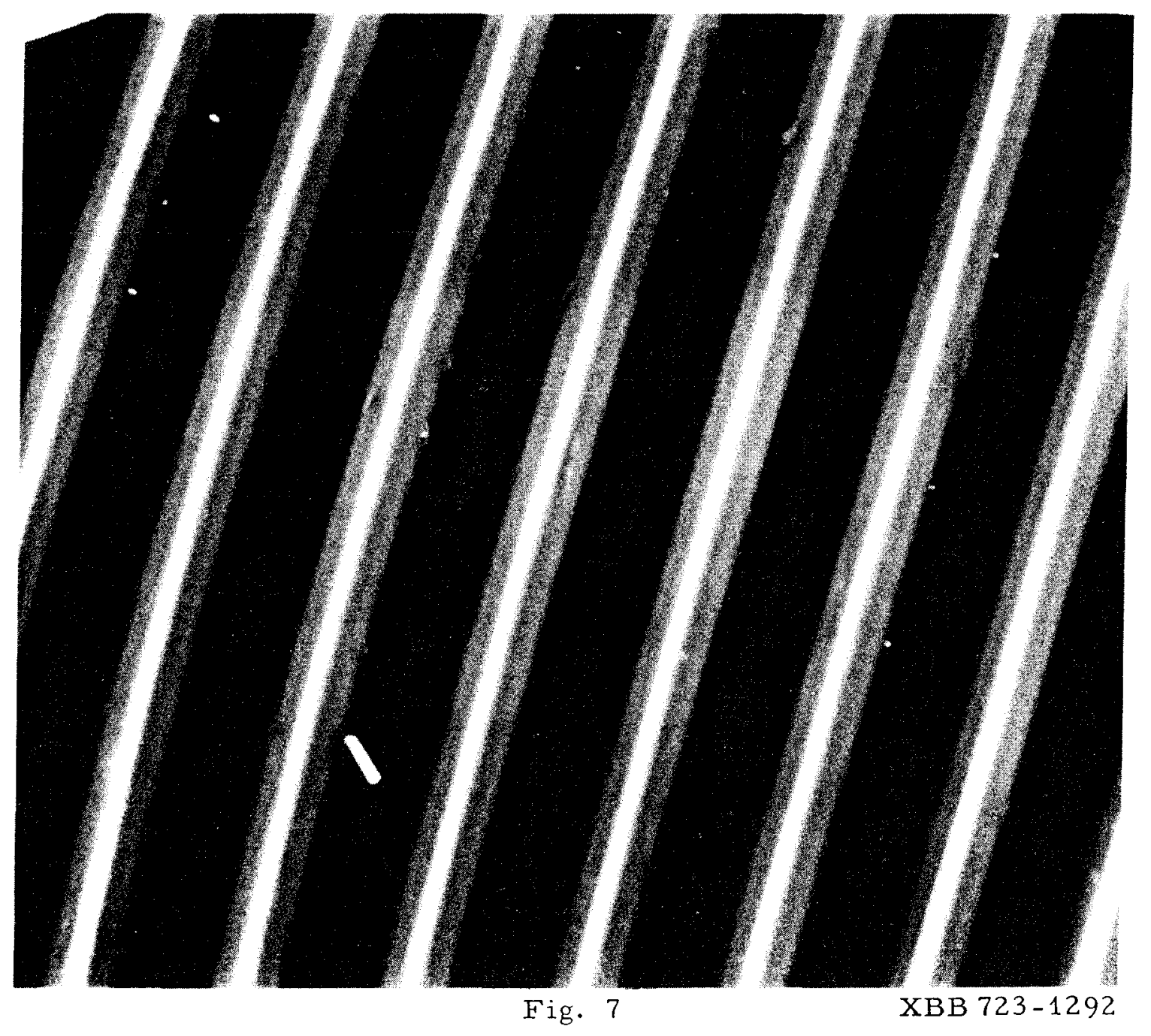




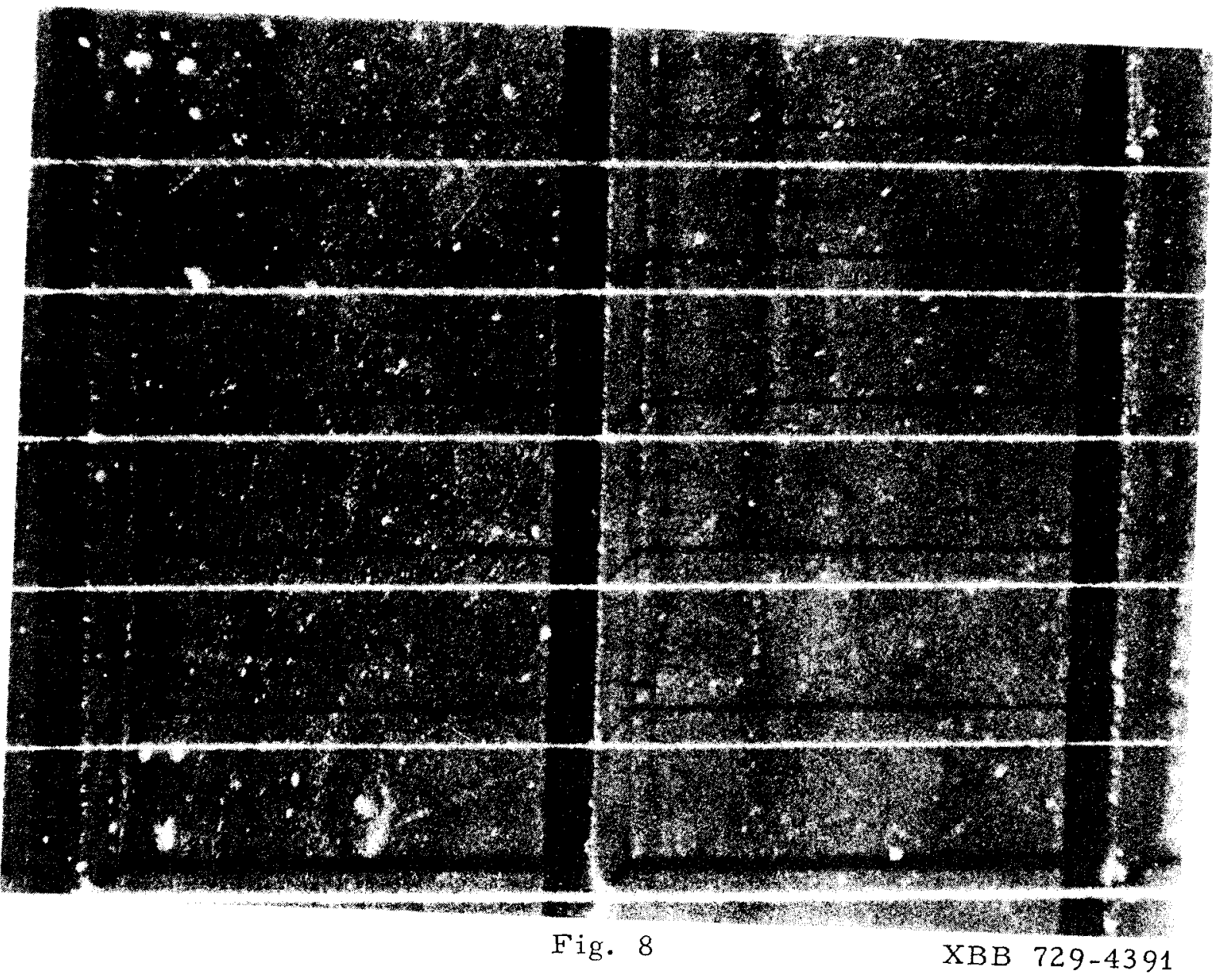




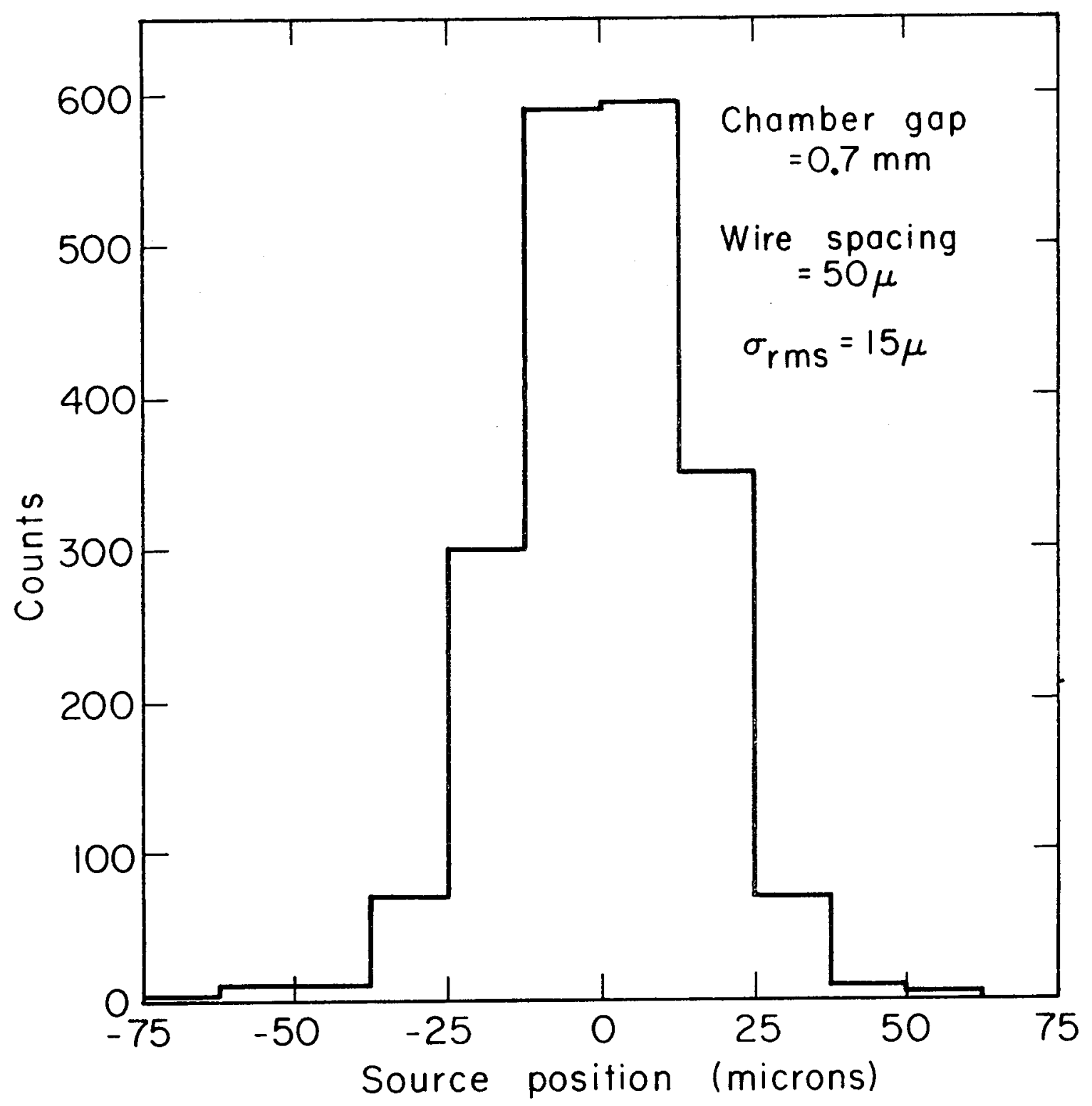

Fig. 9

$X 8 L 716-3718$ 


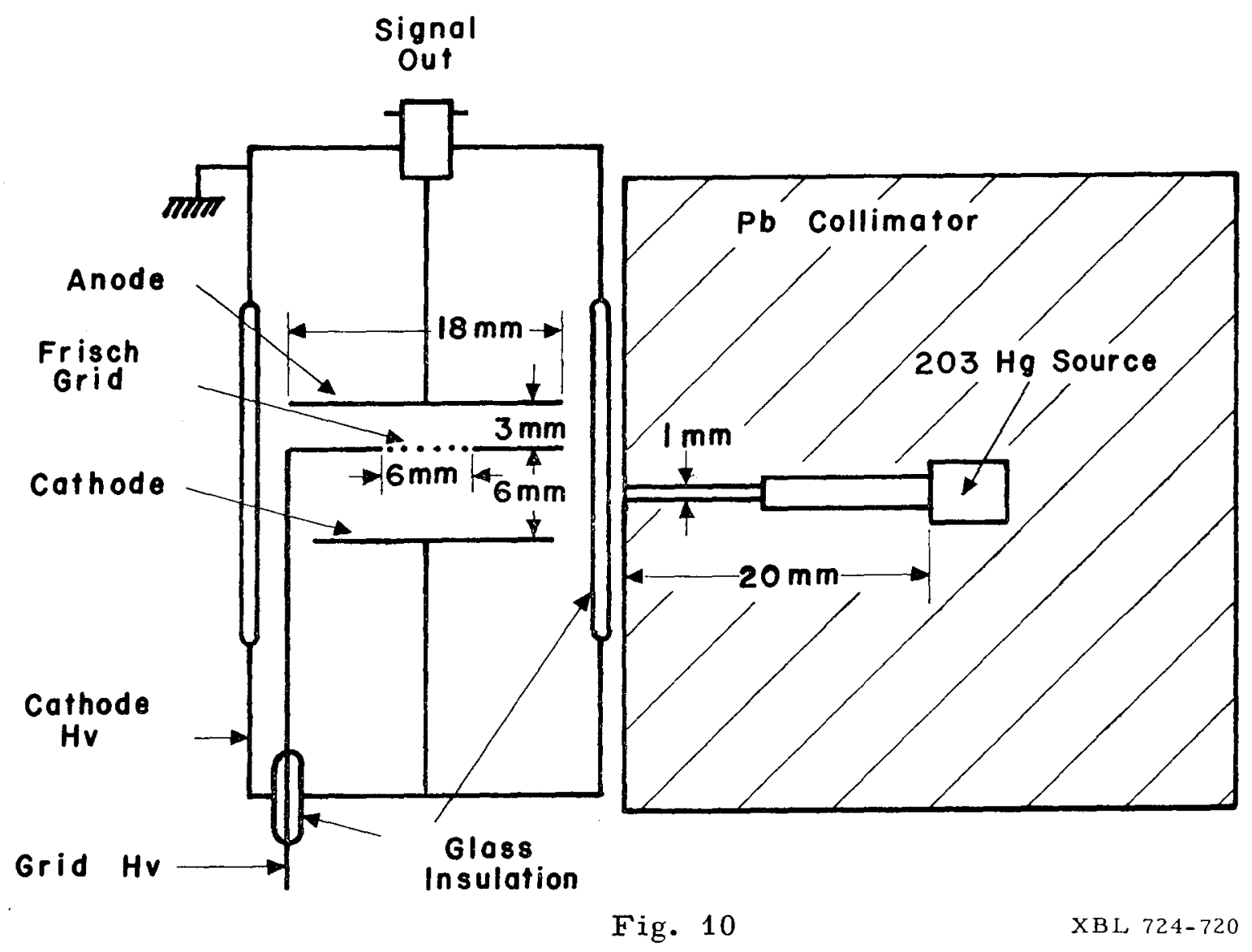




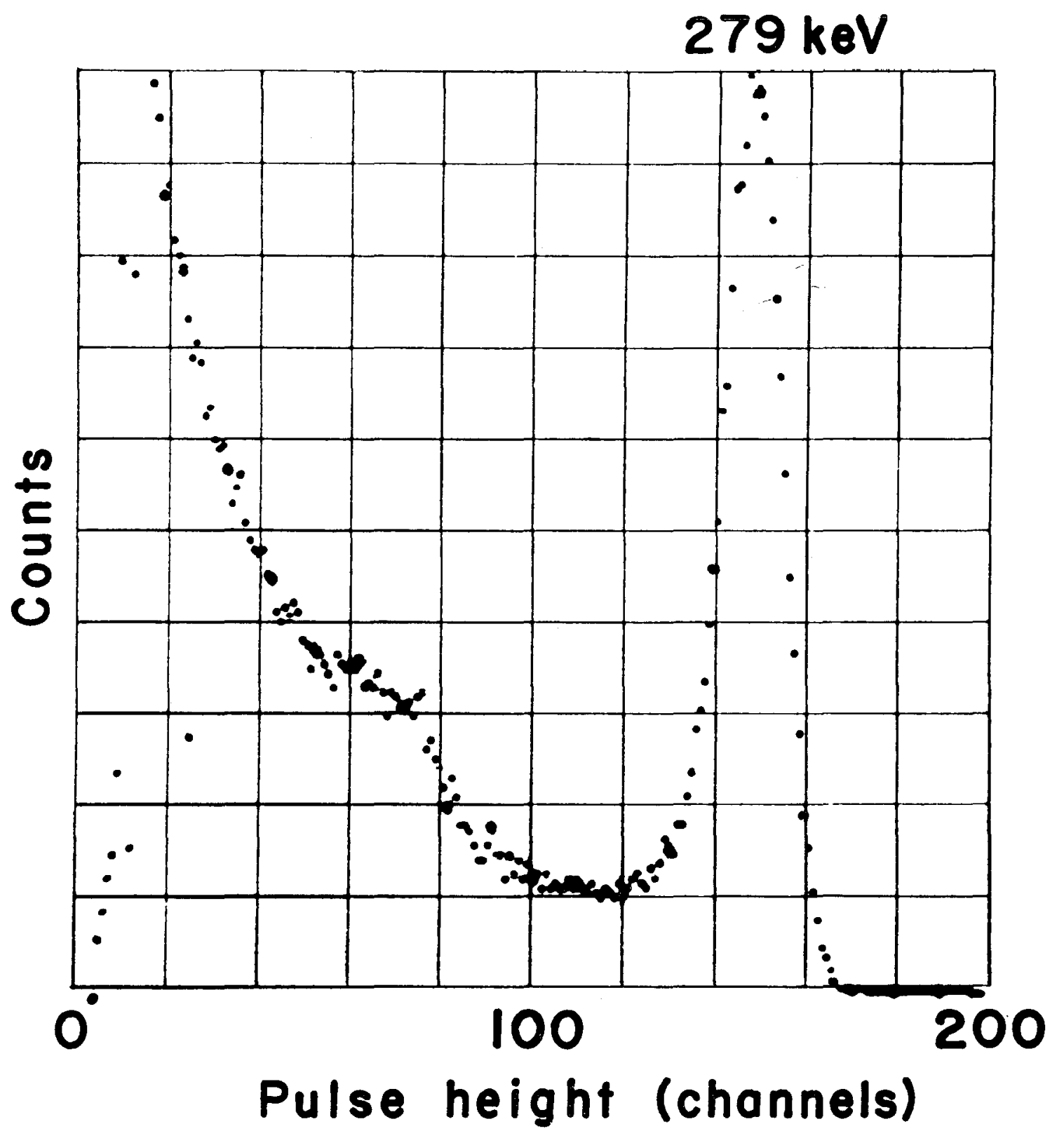

Fig. 11

XBL 724-719 